DOI: http://dx.doi.org/10.17793/rdd.v5i8.875

\title{
5. ANTÍGONA E A RESISTÊNCIA ANTE A LEI INJUSTA
}

\section{ANTIGONA AND RESISTANCE AGAINST UNJUST LAW}

Ney Wiedemann Neto ${ }^{1}$

\begin{abstract}
RESUMO: O texto examina a peça "Antígona", de Sófocles, e a sua atualidade, numa aproximação entre o Direito e a Literatura, com foco na questão da resistência ante a lei injusta através da desobediência civil.
\end{abstract}

PALAVRAS-CHAVE: Antígona; Sófocles; Direito; Literatura.

ABSTRACT: The text examines the play "Antígona" by Sófocles, and its relevance in a rapprochement between Law and Literature, focusing on the issue of resistance against the unjust law through civil disobedience.

KEY-WORDS: Antígona; Sófocles; Law; Literature.

Sumário: Introdução; 2. A questão da lei injusta; 3. A questão da desobediência civil; 4. Considerações finais, Referências bibliográficas.

\section{INTRODUÇÃO}

Antígona é uma obra literária de uma absoluta profundidade e de uma complexidade intensa, que exige do leitor atento a capacidade de ver além. De construir respostas para questionamentos que permeiam o caminho traçado pela humanidade há séculos. A Professora Kathrin H. Rosenfield lembra que grandes pensadores ocidentais já se debruçaram sobre a obra literária Antígona, em um esforço de análise. Goethe, Schlegel e Hegel foram alguns desses pensadores, sendo que este último apresentou uma importante contribuição à interpretação da peça Antígona pela sutileza e complexidade com que analisou a obra prima de Sófocles. Ou nas palavras da Professora Kathrin H. Rosenfield:

\footnotetext{
${ }^{1}$ Desembargador do Tribunal de Justiça do Rio Grande do Sul. Mestre em Poder Judiciário, FGV Direito Rio. Professor do Curso de Direito da Faculdade Inedi CESUCA, Cachoeirinha-RS. E-mail: neyneto@cesuca.edu.br.
} 


\section{Revista Diálogos do Direito \\ http://ojs.cesuca.edu.br/index.php/dialogosdodireito/index \\ ISSN 2316-2112}

(...) diferentemente de Goethe e Schlegel, ele fornece uma interpretação bem mais complexa e sutil, pondo em relevo múltiplas oposições interconectadas das quais brotam conflitos diversos. ${ }^{2}$

Certamente que a obra Antígona permite diversas interconexões com as mais diversas áreas do conhecimento humano. E o Direito não poderia estar fora do alcance e da profundidade da obra trágica Antígona, pois:

A tragédia reflete sobre a organização social, os modos de governar e de fazer justiça e a possibilidade de conter conflitos e de encarar as contradições fundamentais da existência humana. ${ }^{3}$

Dessa forma, antes de uma abordagem que leve em consideração aspectos do Direito presentes nessa obra de Sófocles, é fundamental uma pequena apresentação da história, com rápida referência às suas personagens e aos seus conflitos. Antígona é uma das filhas do Rei Édipo, cuja história trágica reverbera pelos séculos, pois este matou seu próprio pai, o Rei Laio, e casou-se com sua mãe, Jocasta. Irmã de Ismena, de Etéocles e de Polínices, Antígona nasce do incesto do Rei Édipo com sua própria mãe, Jocasta, portanto, sua mãe é ao mesmo tempo também sua avó. Antígona é uma personagem de grande significado na obra trágica, pois sendo uma mulher, lhe caberia os assuntos domésticos, a vida privada no seio da Pólis, pois no século quinto antes de Cristo, nas cidades Gregas, as mulheres eram muito pouco consideradas, tratadas como seres inferiores. Porém, Antígona se imiscui nos assuntos da política, nos assuntos da vida pública da pólis e reivindica: quer enterrar na cidade o corpo de seu irmão morto, Polínices, que ainda se encontra insepulto, pois assim exigem os deuses das terras de baixo, ou seja, do Hades. Segundo as leituras de Goethe e Schlegel, Antígona é apresentada "como a figura da justiça absoluta, que tem todo o direito e toda a beleza de seu lado." ${ }^{4}$

Etéocles e Polínices são atingidos pela imprecação que o Rei Édipo lançara sobre seus dois filhos varões e amaldiçoados, e que combatiam entre si pela disputa do trono da cidade de Tebas. Ao empreender a guerra contra seu irmão, Etéocles, Rei de Tebas, busca defender a cidade da tentativa de tomada do poder por Polínices. Ocorre que durante o duelo travado entre eles, ambos acabam por morrer na batalha, derramando o sangue no solo da cidade de Tebas, como prenuncio de tragédias vindouras. Etéocles é enterrado com as honras devidas ao grande rei tebano, subindo ao poder o tio dos irmãos mortos, e também tio de Antígona e Ismena: Creonte. Explica Kathrin H. Rosenfield que:

Antígona e Creonte pertencem a duas linhagens distintas. Édipo e Laio descendem de uma linhagem de reis, dos Labdácidas, ao passo que Creonte pertence a um ramo de

2 ROSENFIELD, Kathrin. Sófocles \& Antígona. Filosofia Passo-a-Passo. Vol. 9. Rio de Janeiro, Jorge Zahar Editor, 2002, p. 8.

3 Op. Cit. p. 07.

4 Op. Cit. p. 08. 
conselheiros reais e regentes. Ele e seus ancestrais Menoekeus e Oklasos governam apenas em situações emergenciais. ${ }^{5}$

Digno de transcrição é o comentário de apresentação da obra feita pelo tradutor de Antígona para a Língua Portuguesa, Donaldo Schüller:

Antígona é uma peça de fortes contrastes. Onde convocar forças para derrubar o tirano quando cidadãos respeitáveis calam? Sófocles coloca em cena uma mulher sem partidários, sem exército, sem nada. Antígona abala a tirania sozinha. E isso numa sociedade em que a vida pública era de exclusiva competência masculina. O homem é terrível (deinós), dirá o coro. Preserve-se a ambiguidade. O homem é terrível no crime e na virtude, em altos pensamentos e atitudes intempestivas, na opressão e na luta pela liberdade. Antígona morre? Morre! Morre como poucos. Morre para dignificar todos os que em todas as épocas atacam a injustiça. Não há tormento maior do que viver como Creonte, o tirano - entre ruínas espalhadas pelos seus desatinos. Antígona é uma aventura de lealdade, dignidade, linguagem, vida.

Nesse sentido, lembra-nos Kathrin Rosenfield que esses mitos milenares foram transmitidos de geração em geração pela tradição oral, isto é, uma espécie de educação pela narrativa, que transmite os valores e regras fundamentais da sociabilidade. Eis por que os cultos, intimamente ligados aos mitos, são a própria manifestação da vida pública que, por sua vez, fornece o fundamento às instituições da cidade:

$\mathrm{Na}$ época clássica, os poetas retomam os mitos antigos, isolando alguns episódios da frouxa integração na narrativa oral. Nessa reescritura, o passado remoto da lenda heroica transforma-se em pano de fundo para uma reflexão sobre problemas atuais. A tragédia reflete sobre a organização social, os modos de governar e de fazer justiça e a possibilidade de conter conflitos e de encarar as contradições fundamentais da existência humana. O teatro grego é o símbolo de uma feliz integração do conservadorismo religioso com ousadíssimas inovações sociais e políticas. ${ }^{6}$

Creonte ordena que Polínices, que atacara a cidade, fique insepulto. Antígona insurge-se e enterra o irmão, consoante determinavam os costumes religiosos da época. Por sua desobediência, Antígona é condenada à morte por Creonte. Em Antígona vamos encontrar uma referência ao direito natural, em oposição ao direito positivo. Ainda, a reflexão a respeito do direito de resistência e da desobediência civil, em face da lei injusta, em face do arbítrio do governante, que decidiu de modo contrário à ordem natural das coisas.

5 Op. Cit. p. 11.

${ }^{6}$ Op. Cit. p. 09. 
Assim, nesta aproximação entre a Literatura e o Direito, serão examinadas essas duas questões relevantes, da lei injusta e da possibilidade de resistência, através da resistência civil, do que essa peça é, quiçá, a mais remota referência.

\section{A QUESTÃO DA LEI INJUSTA}

Ainda no prólogo, Antígona expõe para a irmã Ismene seu plano de sepultar o irmão, violando o decreto de Creonte. Ismene pondera que não é possível se opor à força da lei e à decisão soberana do tirano. Ela afirma que devem submeter-se às duras leis e a quem está no poder. Assume uma posição de conformismo e de submissão, mesmo ante a injustiça. Já Antígona, pelo contrário, entende que deve fazer o que é certo, ainda que sob o risco de arcar com severas punições pela sua transgressão.

Já no segundo episódio, o fato está consumado. Antígona, confrontada por Creonte, confessa sem rodeios que violou a proibição de enterrar seu irmão (linhas 445-455). Questionada como ousou transgredir as leis de Creonte, Antígona apresenta o argumento que essas leis seriam contrárias a Zeus. Aqui, o autor traz a questão do direito natural, com origem religiosa, sobrenatural, porque o direito dos homens deveria estar conforme as leis divinas. Assim argumentou Antígona, ao justificar o motivo de desobedecer à lei de Creonte:

Não foi, com certeza, Zeus que as proclamou, nem a Justiça com trono entre os deuses dos mortos as estabeleceu para os homens. Nem eu supunha que tuas ordens tivessem o poder de superar as leis não-escritas, perenes, dos deuses, vistos que és mortal. Pois elas não são de ontem nem de hoje, mas são sempre vivas, nem se sabe quando surgiram. Por isso, não pretendo, por temor às decisões de algum homem, expor-me à sentença divina. Sei que vou morrer.

Mais adiante, já no terceiro episódio, Creonte afirma que a situação de desobediência à lei praticada por Antígona impunha-lhe o dever de puni-la. Se não o fizesse, poderia passar por mentiroso na cidade. Creonte acreditava que ao tolerar a infração, perderia a autoridade sobre os demais cidadãos. No caso, havia também outra questão, do parentesco, em que Creonte ponderava que não poderia abrir exceções em razão de vínculos familiares. Por fim, assim justifica o tirano, sinalizando a posição sob análise do dever de obediência, mesmo à lei injusta (linhas 660-670):

$\mathrm{O}$ insolente, o transgressor das leis, o que se opõe às autoridades, não conte com meu aplauso. A que a cidade conferiu poder, a este importa obedecer, seja nas grandes questões seja nas justas ... e até nas injustas.

Percebe-se aí, aliás, um reconhecimento de que a sua decisão poderia até mesmo ser injusta, 


\section{Revista Diálogos do Direito \\ http://ojs.cesuca.edu.br/index.php/dialogosdodireito/index}

ISSN 2316-2112

mas ele não via como voltar atrás, sem que isso fosse percebido como um sinal de fraqueza, inaceitável a quem está investido de autoridade. O tirano, nesse momento, argumenta que do contrário haveria a anarquia, e que vidas prosperam e são salvas, inclusive nas guerras, pela obediência.

Por fim, no aspecto sob a análise, destaca-se o argumento de Hêmon, filho de Creonte, que pondera no sentido que nessas questões não há uma única verdade, uma única possibilidade de decisão que seja justa, sábia e adequada. Assim, entende que o governante, para decidir, deveria refletir e analisar todos os lados e aspectos da relação. Hêmon assim sugeriu ao pai (linhas 700-715):

Não carregues em ti só uma morada da verdade: o que tu dizes, nada mais que isso. Quem julga deter saber exclusivo, possuir língua e mente estranhas aos demais, nesse, se o abres, veras o vazio. Para o homem, ainda que seja sábio, aprender continuamente e ser flexível não é vergonhoso.

Talvez essa decisão de Creonte seja, na literatura, um dos mais antigos exemplos ou a origem daquilo que na prática do direito, junto aos tribunais, passou-se a denominar de "argumento de autoridade”. Ou seja, é uma decisão que não se justifica e não se fundamenta no sistema jurídico, tendo validade pelo poder de que está investido aquele de quem emana. Muitas vezes essa crítica é feita inclusive às decisões dos magistrados, no processo judicial. Para mitigar essa hipótese, justificam alguns doutrinadores que o art. 489 do novo Código de Processo Civil ${ }^{7}$ traz uma série de aspectos que o magistrado deve observar para validar a sua decisão, no plano da fundamentação.

\footnotetext{
${ }^{7}$ Art. 489. São elementos essenciais da sentença:

I - o relatório, que conterá os nomes das partes, a identificação do caso, com a suma do pedido e da contestação, e o registro das principais ocorrências havidas no andamento do processo;

II - os fundamentos, em que o juiz analisará as questões de fato e de direito;

III - o dispositivo, em que o juiz resolverá as questões principais que as partes lhe submeterem.

$\S 1$ o Não se considera fundamentada qualquer decisão judicial, seja ela interlocutória, sentença ou acórdão, que:

I - se limitar à indicação, à reprodução ou à paráfrase de ato normativo, sem explicar sua relação com a causa ou a questão decidida;

II - empregar conceitos jurídicos indeterminados, sem explicar o motivo concreto de sua incidência no caso;

III - invocar motivos que se prestariam a justificar qualquer outra decisão;

IV - não enfrentar todos os argumentos deduzidos no processo capazes de, em tese, infirmar a conclusão adotada pelo julgador;

$\mathrm{V}$ - se limitar a invocar precedente ou enunciado de súmula, sem identificar seus fundamentos determinantes nem demonstrar que o caso sob julgamento se ajusta àqueles fundamentos;

VI - deixar de seguir enunciado de súmula, jurisprudência ou precedente invocado pela parte, sem demonstrar a existência de distinção no caso em julgamento ou a superação do entendimento.

$\S 2$ o No caso de colisão entre normas, o juiz deve justificar o objeto e os critérios gerais da ponderação efetuada, enunciando as razões que autorizam a interferência na norma afastada e as premissas fáticas que fundamentam a conclusão.

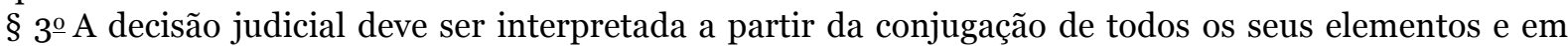
conformidade com o princípio da boa-fé.
} 


\section{Revista Diálogos do Direito \\ http://ojs.cesuca.edu.br/index.php/dialogosdodireito/index}

ISSN 2316-2112

Aristóteles, na Arte Retórica, ao escrever sobre justiça e equidade, assim se posicionou a respeito das palavras de Antígona:

Digo que, de um lado, há a lei particular e, do outro lado, a lei comum: a primeira varia segundo os povos e define-se em relação a estes, quer seja escrita ou não-escrita; a lei comum é aquela que é segundo a natureza. Pois há uma justiça e uma injustiça, de que o homem tem, de algum modo, a intuição, e que são comuns a todos, mesmo fora de toda comunidade e de toda convenção recíproca. É o que expressamente diz a Antígona de Sófocles, quando a despeito da proibição que lhe foi feita, declara haver procedido justamente, enterrando Polinices: era esse seu direito natural: Não é de hoje, nem de ontem, mas de todos os tempos que estas leis existem e ninguém sabe qual a origem delas. ${ }^{8}$

Para aqueles que aceitam o chamado "direito natural", os homens são guiados por certos princípios morais e religiosos, que não se explicam e não se acham positivados em normas escritas. Esses princípios são invocados quando as normas escritas se acham em oposição a eles. Nessa ótica, haveria princípios morais e religiosos acima da lei positiva. É uma questão que é discutida milenarmente, e que segue sendo atual no debate das ideias.

Oportuna é a contribuição que nos traz Clóvis Barros Filho, com suas considerações sobre a questão do poder. Pondera o autor que o exercício do poder de um sobre o outro pressupõe que as relações sociais são marcadas por desigualdades. E tais diferenças entre as pessoas precisam ser legitimadas. Essa questão da legitimação, corrente em filosofia política, é bem abordada na obra "A República", de Platão. Para o filósofo, nem todos nasceram para o exercício da governança. Apenas uma minoria seria digna das funções mais importantes. Platão entendia por poder uma força exercida sobre os outros de forma legítima. E, ainda, considera que os filósofos seriam as pessoas mais qualificadas para essa função de governar, de exercer o poder, pelo conhecimento que detém e porque são aqueles que buscam o bem. Cita, ainda, em uma visão contemporânea, Michel Foucault, que trata a questão do poder sob a ótica da dominação. Aborda a falta de liberdade no exercício do poder, enquanto relação. Tem a ver com a aceitação do seu exercício. O motivo porque alguém obedece e acata as ordens daquele que manda 9 .

E prossegue o citado autor, sobre as questões de justiça e lei, e o dilema se somos livres para agir de modo contrário a lei:

Em Sófocles, encerra a sua trilogia tebana a história de Antígona. Uma das filhas de Édipo que, herdando o destino desgraçado do pai, se vê diante de uma difícil escolha. Seus irmãos Polínices e Etéocles morrem combatendo um ao outro pelo trono de Tebas - Sim, é uma

\footnotetext{
${ }^{8}$ ARISTÓTELES. A arte retórica e arte poética. Trad. Antônio Pinto de Carvalho. São Paulo: Difusão Europeia do Livro, 1959, p. 86.

9 BARROS FILHO, Clóvis. A filosofia explica as grandes questões da humanidade. São Paulo: Casa do Saber, 2013, p. 68-89.
} 
família complicada! -. Mortos ambos, assume o lugar disputado seu tio Creonte que, ato primeiro de sua majestade, decreta a proibição de se enterrar e fazer as honras fúnebres a seu sobrinho Polínices, que morrera atacando a cidade de Tebas. As leis religiosas determinavam que cabia aos parentes enterrar e fazer as honras fúnebres. Sem estes rituais, o espírito do morto vagaria sem lar e destino pelo mundo, como uma alma penada, sem que tivesse sua sede e fome saciadas por libações - libação é um apelido sofisticado para despacho de oferendas a santos. Eis Antígona dividida. Por um lado, tem o dever religioso de enterrar seu irmão. Por outro, uma lei da cidade proíbe este mesmo ato. O que fazer? O que é mais justo? Ela decide, por amor e piedade, enterrar seu irmão. É flagrada em desrespeito à lei e levada até seu tio, o rei de Tebas. Legislador e juiz da lei violada. Creonte lhe pergunta se não sabia do édito que proibia o enterro. Antígona sabia, diz que não desrespeitou a lei de Creonte por ignorância e nem o fez com vergonha, apesar de sua situação de ré. $\mathrm{O}$ fez com orgulho de quem fazia algo justo, pois para ela, justiça é agir de acordo com a mais bela e melhor das justiças, a justiça divina. Justiça natural ${ }^{10}$.

A esse respeito, aliás, Hans Kelsen não foi omisso na sua percuciente análise sobre a ideia de liberdade como fundamento da justiça:

Um princípio de justiça do mais alto valor político é o que se apresenta com base num sistema moral em que a liberdade individual é tida como o valor supremo. A ideia originária de liberdade tem caráter puramente negativo. É o postulado individualista de que o homem deve ser livre, quer dizer, não estar submetido a qualquer ordem normativa que regule a sua conduta em face dos outros e limite, consequentemente, a sua liberdade individual. É uma norma que exclui a validade de todas as normas sociais que limitam a liberdade individual. Nesta sua forma originária, a ideia da liberdade é um princípio associal, anti-social mesmo. Como princípio moral, ou seja, afinal, como princípio social e particularmente como princípio de justiça, a ideia de liberdade tem de sofrer transformação. A liberdade (=libertação) $d a$ ordem normativa tem de tornar-se em liberdade $s o b$ a ordem normativa, a liberdade individual tem de transformar-se em liberdade social. Se tem de existir uma ordem normativa que vincule os homens na sua conduta recíproca, ela apenas poderá ser uma ordem erigida com base no assentimento dos indivíduos que lhe vão ficar submetidos. Pois o homem apenas deve, ou - como por vezes também se formula - apenas pode ser vinculado através de sua própria vontade ${ }^{11}$.

Há aqui uma terceira via importante à discussão da liberdade enquanto "natural" versus "previsão do direito positivo": a concepção de liberdade em Espinosa, que foi retomada posteriormente por filósofos como Foucault e Deleuze. Na concepção espinosista, liberdade não seria "livre arbírio" uma vez que se somos extensões da natureza, não haveria espaço para a liberdade. A liberdade só é adquirida enquanto "produção de si" ou "estética da existência". Essa linha é praticamente ignorada pelo pensamento preponderante na filosofia do direito.

Com Paulo Nader, é oportuno recordar a respeito da insuficiência do direito positivo e da importância do direito natural:

\footnotetext{
${ }^{10}$ Op. cit. P. 99-100.

${ }^{11}$ KELSEN, Hans. A Justiça e o Direito Natural. Trad. João Baptista Machado. Armênio Amado, Editor, Sucessor. $2^{\text {a }}$. ed. Coimbra, 1979, p. 62-63.
} 
O motivo fundamental que canaliza o pensamento ao Direito natural é a permanente aspiração de justiça que acompanha o homem. Este, em todos os tempos e lugares, não se satisfaz apenas com a ordem jurídica institucionalizada. O Direito positivo, visto como expressão da vontade do Estado, é um instrumento que tanto pode servir à causa do gênero humano, como pode consagrar valores negativos que impedem o pleno desenvolvimento da pessoa. Por inclinação, ao questionar o Direito positivo vigente, o homem busca, em seu próprio sentimento de justiça e de acordo com a sua visão sobre a ordem natural das coisas, encontrar a legitimidade das normas que lhe são impostas. $\mathrm{O}$ contrário, a atitude acrítica, seria a admissão de que não existe, para o legislador, qualquer limite ou condicionamento na tarefa de estruturar a ordem jurídica. ${ }^{12}$

E, modernamente, essa questão do Direito natural evoluiu no nosso ordenamento para o reconhecimento dos princípios como fonte do Direito e o seu reconhecimento como critério de validação do sistema. Abriu-se espaço para a Teoria da Argumentação Jurídica, como superação do Positivismo Jurídico e para a ponderação dos princípios representativos de valores que validam as normas jurídicas.

\section{A QUESTÃO DA DESOBEDIÊNCIA CIVIL}

A desobediência de Antígona foi um ato contra o poder de Creonte, contra as leis do Estado, contra o princípio do direito soberano. A desobediência civil é entendia como uma forma de protesto político não violento, que se opõe a alguma ordem que possui algum comportamento de injustiça ou contra um governo que é visto como opressor pelos desobedientes.

É importante relevar que a noção e a prática da desobediência civil pressupõem a democracia e o Estado de direito. Poderíamos contestar a análise da Antígona em termos de desobediência civil ao lembrarmos que a Tebas de Creonte e Antígona não era propriamente uma democracia. No entanto, se considerarmos, como François Ost, que Sófocles construiu uma cidade fictícia, com vistas a estabelecer um laboratório social onde se experimenta o limite social, é possível "ver na cidade tebana uma coletividade política pré-democrática". ${ }^{13}$ Isso possibilita colocar a questão do poder partilhado, no âmbito do qual o tema do conhecimento do justo pelo indivíduo torna-se pertinente. Além disso, afirma o filósofo belga, a atitude de Antígona comporta tantos traços da desobediência civil que não seria impertinente analisá-la nesses termos. Fazendo uma confrontação com as características da desobediência civil apontadas por Falcon y Tella, François Ost considera que o comportamento de Antígona, em essência, releva esse tipo de conduta, pois se trata de uma transgressão de uma regra de direito positivo; inscreve-se no espaço do direito público apelando à consciência pública; é

${ }^{12}$ NADER, Paulo. Introdução ao estudo do direito. Rio de Janeiro: Forense, 1982, p. 455.

${ }^{13}$ OST, François. Raconter la loi - Aux sources de l'imaginaire juridique. Paris: Odile Jacob, 2004, p. 196. 


\section{Revista Diálogos do Direito \\ http://ojs.cesuca.edu.br/index.php/dialogosdodireito/index}

ISSN 2316-2112

fundamentalmente pacífica e não violenta; o transgressor assume o risco da sanção; o transgressor faz apelo a "princípios superiores". ${ }^{14}$

Isso nos leva à importante questão das possibilidades que temos de nos opor à lei injusta. Seria isso desobediência civil? Plauto Faraco de Azevedo aborda essa questão com propriedade:

Ora, é perfeitamente sensato e, por vezes mesmo necessário, falar de leis ou de decisões injustas, o que faz supor a existência de um padrão "independente e superior ao direito positivo", segundo o qual se possa avaliá-lo. Por isso, a necessidade do direito natural é a mesma, tanto hoje como no passado. Muito embora se tenha adotado o propósito de, por agora, não tomar partido relativamente à problemática do direito natural, é forçoso registrar o efetivo ressurgimento desta ideia logo após o início do presente século, quase simultaneamente na Itália, França e Alemanha, vindo a colocar-se em primeiro plano como alternativa ao positivismo jurídico. As tendências que neste sentido primeiramente se manifestaram já antes da Primeira Guerra Mundial foram reforçadas pela emergência do totalitarismo e das ditaduras. Ao aceitarem a legislação dessas ditaduras totalitárias, quer fascistas, quer comunistas, como formas de direito, os positivistas se perderam. Proclamar a legitimidade de uma norma legal só porque Hitler assim o quis constitui aberração que só pode ser evitada mediante o encontro de um padrão válido fora e além do direito ${ }^{15}$.

No mesmo sentido é a reflexão acurada e profunda de Dennis Lloyd, a respeito das motivações que ensejaram o ressurgimento do direito natural no pós-guerra:

As razões justificativas do mais recente ressurgimento do direito natural não são difíceis de encontrar. A ascensão das ditaduras nazista e fascista, a expansão do totalitarismo, a estarrecedora selvageria do massacre de milhões de pessoas inocentes em nome da ideologia racial, e o repúdio deliberado por grandes e poderosas nações de todas as normas de moralidade e cultura que têm sido consideradas os elementos indispensáveis na civilização humana, culminaram em muitas apreensões e no reexame dos princípios da lei e do governo humanos. Poderá ser realmente verdade, como os positivistas insistiram tão sistematicamente em afirmar, que a lei humana seja considerada válida e merecedora de obediência, independentemente do seu conteúdo moral e do grau em que imponha uma conduta contrária a todos os padrões morais ou civilizados recebidos? ${ }^{16}$

Com Luís Roberto Barroso ${ }^{17}$, lembramos que o positivismo filosófico foi fruto de uma idealização do conhecimento científico, uma crença romântica e onipotente de que os múltiplos domínios da indagação e da atividade intelectual pudessem ser regidos por leis naturais, invariáveis, independentes da vontade e da ação humana. $\mathrm{O}$ homem chegara à sua maioridade racional e tudo passara a ser ciência: o único conhecimento válido, a única moral, até mesmo a única religião. O universo, conforme divulgado por Galileu, teria uma linguagem

14 Idem, p. 197-198.

${ }^{15}$ AZEVEDO, Plauto Faraco de. Limites e justificação do poder do Estado. Petrópolis: Vozes, 1979, p. 44.

${ }^{16}$ LLOOYD, Dennis. A ideia de lei. São Paulo: Martins Fontes, 1985, p. 70.

17 BARROSO, Luís Roberto. Curso de Direito Constitucional Contemporâneo: os conceitos fundamentais e a construção do novo modelo. $4^{\mathrm{a}}$. ed. São Paulo: Saraiva, 2013, pp. 261-264. 
matemática, integrando-se a um sistema de leis a serem descobertas, e os métodos válidos nas ciências da natureza deviam ser estendidos às ciências sociais.

O positivismo jurídico aplica os fundamentos do positivismo filosófico no mundo do direito, na pretensão de criar uma ciência jurídica, com características análogas às ciências exatas e naturais. A busca da objetividade científica com ênfase na realidade observável e não na especulação filosófica, apartou o direito da moral e dos valores transcendentes. Direito é norma, ato emanado do Estado com caráter imperativo e força coativa. A ciência do direito, como todas as demais, deve se fundar em juízos de fato, que visam ao conhecimento da realidade, e não em juízos de valor, que representam uma tomada de posição diante da realidade. Não é no âmbito do direito que se deve tratar a discussão acerca das questões como legitimidade e justiça.

O positivismo tornou-se, nas primeiras décadas do Século XX, a filosofia dos juristas. A teoria jurídica empenhava-se no desenvolvimento de ideias e de conceitos dogmáticos, em busca da cientificidade anunciada. O direito reduzia-se ao conjunto de normas em vigor. Considerava-se um sistema perfeito e, como todo dogma, não precisava de qualquer justificação além da própria existência.

Conceitualmente, jamais foi possível a transposição totalmente satisfatória dos métodos das ciências naturais para a área das humanidades. $\mathrm{O}$ direito, ao contrário dos outros domínios, não tem nem pode ter uma postura puramente descritiva da realidade, voltada para relatar o que existe. Cabe-lhe prescrever um dever-ser e fazê-lo valer nas situações concretas. O direito tem a pretensão de atuar sobre a realidade, conformando-a e transformando-a. Ele não é um dado, mas uma criação. A relação entre o sujeito do conhecimento e seu objeto de estudo - isto é, entre o interprete, a norma e a realidade - é tensa e intensa. O ideal positivista de objetividade e neutralidade é insuscetível de se realizar.

A decadência do positivismo é emblematicamente associada à derrota do fascismo na Itália e do nazismo na Alemanha. Esses movimentos políticos e militares ascenderam ao poder dentro do quadro de legalidade vigente e promoveram a barbárie em nome da lei. Os principais acusados de Nuremberg invocaram o cumprimento da lei e a obediência a ordens emanadas de autoridade competente. Ao fim da Segunda Guerra Mundial, a ideia de um ordenamento jurídico indiferente a valores éticos e da lei como uma estrutura meramente formal, uma embalagem para qualquer produto, já não tinha aceitação no pensamento esclarecido. 


\section{CONSIDERAÇÕES FINAIS.}

As doutrinas éticas fundamentais se desenvolveram em diferentes épocas e em diferentes sociedades, como resposta aos problemas sociais. Há uma vinculação entre os conceitos morais e a realidade humana. Cada doutrina, por estar sempre em processo de mudança, tem relação com outra. Deve-se, entretanto, atentar para a história das ideias, para os conteúdos fundamentais, e para a ética na argumentação, uma vez que a falácia é também muitas vezes percebida e destruída por quem for debater em grandes decisões políticas, ou controvérsias filosóficas ou judiciais.

A consagrada peça de Sófocles, Antígona, que encerra a tríade tebana, nos conduz à questão da justiça e da lei justa, que emana daquele que exerce o poder. A filosofia da justiça propõe eliminar as incertezas sobre o justo e o injusto, afastando a justiça dos sentimentos e das ideias particulares, conduzindo a uma razão pública.

\section{REFERÊNCIAS BILIOGRÁFICAS}

ARISTÓTELES. A arte retórica e arte poética. Trad. Antônio Pinto de Carvalho. São Paulo: Difusão Européia do Livro, 1959.

AZEVEDO, Plauto Faraco de. Limites e justificação do poder do Estado. Petrópolis: Vozes, 1979.

BARROSO, Luís Roberto. Curso de Direito Constitucional Contemporâneo: os conceitos fundamentais e a construção do novo modelo. $4^{\mathrm{a}}$. ed. São Paulo: Saraiva, 2013.

BARROS FILHO, Clóvis. A filosofia explica as grandes questões da humanidade. São Paulo: Casa do Saber, 2013.

KELSEN, Hans. A Justiça e o Direito Natural. Trad. João Baptista Machado. $2^{\mathrm{a}}$ ed. Coimbra: Armênio Amado Editor, 1979.

LLOOYD, Dennis. A ideia de lei. São Paulo: Martins Fontes, 1985.

NADER, Paulo. Introdução ao estudo do direito. Rio de Janeiro: Forense, 1982.

OST, François. Raconter la loi - Aux sources de l'imaginaire juridique. Paris: Odile Jacob, 2004.

ROSENFIELD, Kathrin. Sófocles \& Antígona. Filosofia Passo-a-Passo. Vol. 9. Rio de Janeiro, Jorge Zahar Editor, 2002.

SÓFOCLES. Antígona. Trad. Donaldo Schüler. Porto Alegre: L\&PM Pocket, 2011.

(Artigo submetido em 23/07/2015 e aceito em 20/08/2015) 